\title{
Corticosteroid Injections for Greater Trochanteric Pain Syndrome: A Randomized Controlled Trial in Primary Care
}

\author{
Aaltien Brinks, $M D^{1}$ \\ Rogier M. van Rijn, $P b D^{1}$ \\ Sten P. Willemsen, $\mathrm{MSc}^{2}$ \\ Artbur M. Bobnen, MD, $P b D^{1}$ \\ Jan A. N. Verhaar, MD, PbD \\ Bart W. Koes, $P b D^{1}$
}

Sita M. A. Bierma-Zeinstra, PbD ${ }^{1,3}$

'Department of General Practice, Erasmus Medical Center, University Medical Center Rotterdam, Rotterdam, The Netherlands

${ }^{2}$ Department of Biostatistics, Erasmus Medical Center, University Medical Center Rotterdam, Rotterdam, The Netherlands

${ }^{3}$ Department of Orthopaedic Surgery, Erasmus Medical Center, University Medical Center Rotterdam, Rotterdam, The Netherlands
Conflicts of interest: authors report none.

\section{CORRESPONDING AUTHOR}

Aaltien Brinks, MD

Department of General Practice

Erasmus Medical Center

PO Box 2040

Rotterdam, $3000 \mathrm{CA}$

The Netherlands

a.brinks@erasmusmc.nl

\begin{abstract}
PURPOSE We undertook a study to evaluate the effectiveness of corticosteroid injections in primary care patients with greater trochanteric pain syndrome (GTPS).

METHODS We evaluated the effect of corticosteroid injections compared with expectant treatment (usual care) in a pragmatic, multicenter, open-label, randomized clinical trial in the Netherlands. Patients (aged 18 to 80 years) with GTPS visiting 81 participating primary care physicians were randomly allocated to receive either local corticosteroid injections $(n=60)$ or usual care $(n=60)$. Primary outcomes of pain severity (numerical rating scale 0 to 10) and recovery (yes or no total or major recovery) were evaluated at 3-month and 12-month follow-up visits. Adverse events were collected at 6 weeks.
\end{abstract}

RESULTS At the 3-month follow-up visit, $34 \%$ of the patients in the usual care group had recovered compared with $55 \%$ in the injection group (adjusted $\mathrm{OR}=2.38 ; 95 \% \mathrm{Cl}, 1.14-5.00$, number needed to treat $=5$ ). Pain severity at rest and on activity decreased in both groups, but the decrease was greater in the injection group, for an adjusted difference in pain at rest of $1.18(95 \% \mathrm{Cl}$, $0.31-2.05)$ and in pain with activity of $1.30(95 \% \mathrm{Cl}, 0.32-2.29)$. At the 12 -month follow-up, $60 \%$ of the patients in the usual care group had recovered compared with $61 \%$ in the injection group (OR $=1.05 ; 95 \% \mathrm{Cl}, 0.50-2.27)$. Pain severity at rest and on activity decreased in both groups and the 12-month follow-up showed no significant differences, with adjusted differences of $0.14(95 \% \mathrm{Cl}$, -0.75 to 1.04$)$ for pain at rest and $0.45(95 \% \mathrm{Cl},-0.55$ to 1.46$)$ for pain with activity. Aside from a short period with superficial pain at the site of the injection, no differences in adverse events were found.

CONCLUSION In this first randomized controlled trial assessing the effectiveness of corticosteroid injections vs usual care in GTPS, a clinically relevant effect was shown at a 3-month follow-up visit for recovery and for pain at rest and with activity. At a 12-month follow-up visit, the differences in outcome were no longer present.

Ann Fam Med 2011;9:226-234. doi:10.1370/afm.1232.

\section{INTRODUCTION}

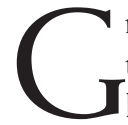
reater trochanteric pain syndrome (GTPS), also known as trochanteric bursitis, is a common cause of hip pain in general practice. In 1958 Anderson described the physical signs of bursitis trochanterica, and in 1979 Little described the clinical findings in the context of other causes of hip pain. ${ }^{1,2}$ Schapira et $\mathrm{al}^{3}$ and Shbeeb and Matteson ${ }^{4}$ reported extended descriptions of the clinical symptoms. Karpinski and Piggott ${ }^{5}$ and Collee et $\mathrm{al}^{6}$ described these clinical findings as GTPS. This syndrome is characterized by chronic intermittent or continuous pain at and around the greater trochanter, sometimes radiating to the lateral aspect of the hip or lateral thigh and increasing with physical activity. There is tenderness to palpation of the greater trochanter on physical examination, reproducing the patient's pain. Although GTPS was previously thought to be 
caused by inflammation of the bursa, recent histological investigation could not confirm this hypothesis. ${ }^{7}$ In 2001 a study of the classification of hip disorders showed that edema around the greater trochanteric tendons (seen on sonography), but not sonographic signs of trochanteric bursitis, was closely related to the symptoms of GTPS. ${ }^{8}$ Magnetic resonance imaging also suggests that pathologic findings of the gluteus medius is associated with GTPS. ${ }^{9}$ Furthermore, Cohen et al recently concluded that fluoroscopically guided corticosteroid injections in the trochantric bursa did not improve the outcome of pain reduction compared with an unguided corticosteroid injection in the trochanteric region. ${ }^{10}$

The prevalence of GTPS was recently calculated to be $17.6 \%$ in a community-based population at risk for knee osteoarthritis and in persons with knee osteoarthritis. ${ }^{11}$ In a retrospective study in general practice, the incidence of patients visiting their primary care physician for trochanteric pain was calculated to be 1.8 persons per 1,000 per year. ${ }^{12}$ This latter study also showed that $36 \%$ of the patients still had complaints after 1 year, and $29 \%$ of the patients still suffered from this pain after 5 years. In that same study $37 \%$ of the patients were injected with corticosteroids, and of these patients, $66 \%$ reported improvement after treatment. ${ }^{12}$ This outcome is similar to the outcome of a case series in which $61 \%$ of patients improved 6 months after a local corticosteroid injection. ${ }^{13}$ In a report of 61 cases, 58 patients had excellent or good results after a corticosteroid injection. ${ }^{14}$ The study comparing unguided corticosteroid injection with fluoroscopically guided injection showed a positive result in $47 \%$ and $41 \%$, respectively. ${ }^{10}$ In another trial corticosteroid injection was compared with other specific therapy (shock wave therapy and exercise therapy) and showed superior short-term effect (success rate 75\% for corticosteroid injections and 13\% and 7\% for shock wave and exercise therapy, respectively) The effect of therapy reversed after 15 months of follow-up (success rate for corticosteroid injection was $48 \%$, shock wave therapy $74 \%$, and exercise therapy $80 \%) .{ }^{15}$

Although local corticosteroid injections are frequently given for GTPS, no study has compared the effect of corticosteroid injections with usual care, which is an expectant approach in a randomized trial. We therefore report the first randomized controlled trial comparing usual care with the effect of an additional local corticosteroid injection in primary care patients with GTPS.

\section{METHODS}

This study was a pragmatic, open-label, randomized trial in general practice conducted in the Netherlands with 81 participating primary care physicians. The local Medical Ethics Committee of the Erasmus University Medical Center, approved the trial, and all the patients gave informed consent for participation. The trial was included in the Dutch Trial register (ISRCTN 16994576). Details of the study protocol were reported in 2007 and are briefly summarized here. ${ }^{16}$

\section{Participants}

General practitioners in the Rotterdam area recruited the study participants by selecting patients (aged 18 to 80 years) who consulted them about GTPS. GTPS was diagnosed when the patient complained of pain persisting for more than 1 week in the lateral region of the hip, and tenderness to palpation of the greater trochanter, reproducing the patient's pain, was found on physical examination. ${ }^{1-4}$

Excluded were patients who were unable to understand the Dutch questionnaires. Also excluded were patients who had consulted their general practitioner with the same symptoms in the previous year and had received any intervention, or who were operated on in the same region, or who had a systemic neurological or rheumatologic disorder.

If the patient was interested in participating in our study, the physician sent to the researcher a fax of the patient's contact information and a standardized form with findings from the physical examination. The physician gave the patients written study information, the baseline questionnaire, and the informed consent form. One of the investigators contacted the patient to ask whether there were any additional questions and assessed the patient's suitability to participate in the study. Patients who were eligible and agreed to participate were asked to return the completed baseline questionnaire and informed consent form.

After the questionnaire was returned, the patient was classified by comorbidity status. If the question, Do you suffer from low-back pain? was positively answered as often or continuously, the patient was classified as having comorbid low-back pain. We used the American College of Rheumatology (ACR) history and physical examination criteria for osteoarthritis of the hip (older than 50 years, morning stiffness lasting longer than 60 minutes, and painful or decreased internal rotation and flexion of the hip as performed by the general practitioner) to decide whether the patient had suspected osteoarthritis of the hip as a comorbid condition. ${ }^{17}$

\section{Randomization}

Patients were independently randomized (based on computerized randomization lists) to receive either the injection therapy or usual care. This randomization 
was stratified by comorbidity and randomization block sizes of 10, yielding 4 strata: with no comorbid condition, with low-back pain, with osteoarthritis of the hip, and with both.

\section{Intervention Treatment}

As soon as randomization had taken place, the general practitioner and the patient were informed about the treatment that the patient would be given. The physicians participating in the study were trained to give the injection according to a standardized procedure: $40 \mathrm{mg}$ of triamcinolone acetate combined with $1 \%$ or $2 \%$ lidocaine in a $5-\mathrm{mL}$ syringe. They were trained to mark the most painful point on the hip on the greater trochanter area with a pen or pencil and to disinfect the site. The needle was inserted perpendicular to the skin, directed down to the point of maximal tenderness, and $1 \mathrm{~mL}$ of the substance was injected at that point The needle was then moved to another place in the painful area, and the same procedure was repeated until the syringe was empty. After the injection the physician sent to the study researchers a fax of a form with the details of the injection given, eg, the volume that was injected, whether the injection was painful, and whether there was pain relief after the injection or any immediate side-effects. In addition to the injection therapy, the physicians were allowed to prescribe analgesics (as in the usual care group). The physicians were also allowed to give a second injection between 3 weeks and 3 months after the first injection.

\section{Usual Care}

The control group received usual care consisting of analgesics as needed. In the Netherlands, because there is direct access to a physiotherapist, all patients in both treatment groups were allowed to receive additional treatment from a physiotherapist (however, the investigators did not specifically recommend this action).

\section{Outcomes}

Primary outcome was recovery at 3 and 12 months as measured on a 7 -point Likert scale ( $1=$ fully recovered to 7 = worse than ever), and severity of pain during the last week (both while at rest and during activity) measured with a numeric rating scale from 0 to $10(0=$ no pain, $10=$ worst conceivable pain). These outcomes were assessed at 6 weeks and at 3, 6, 9, and 12 months after randomization and were collected by means of postal questionnaires.

Other secondary patient-oriented outcomes in this study were quality of life (range 0 to $1,0=$ worst quality of life to 1 = best quality of life), which we measured using a standardized instrument, EQ-5D (EuroQol Group, York, United Kingdom), ${ }^{18}$ and a self-administered health status instrument for patients with osteoarthritis of the hip or knee, the Western Ontario and McMaster University Osteoarthritis Index (WOMAC). The WOMAC index consists of 3 domains: pain (5 items), stiffness (2 items), and function (17 items). We used the domains of pain and function. Each item can be scored on a 5-point Likert scale. (where $1=$ none and $5=$ extreme). Sum scores for each domain were calculated and standardized ( 0 to 100), with high values indicating more pain or lower physical functioning. ${ }^{19}$

At a 6-week follow-up visit, all patients were asked about specific adverse events of the therapy (eg, hot flushes, disturbance in menstruation pattern, or general allergic reaction, such as itching all over the body, urticaria, headache, shortness of breath).

\section{Data Analyses}

Between-group differences in the primary outcome were analyzed based on the intention-to-treat principle. Between-group differences in continuous outcome measures were analyzed with repeated measures for general linear models. Generalized estimating equations models (repeated measures) were used for dichotomous outcome (recovery dichotomized to totally recovered or almost totally recovered vs slightly recovered and less). All analyses were adjusted for baseline values of the outcome, except for the analysis on recovery. In addition, a yes or no presence of comorbidity (osteoarthritis, lowback pain, or both) was added to the regression models. Other baseline values (age, sex, employment, body mass index, education level, and duration of symptoms, preference of treatment, and comorbidity, as well as baseline pain severity for recovery analyses) were assessed to establish whether these values affected the primary outcomes of the study by more than $10 \%$. If so, they were also added to the models. Number needed to treat was calculated for the dichotomized outcome (recovery). Effect sizes were calculated as adjusted difference in outcome divided by baseline standard deviation of the outcome. From the clinical standpoint effect sizes of 0.2 to 0.5 are considered small, and 0.5 to 0.8 moderate, whereas greater than 0.8 indicates a large clinical effect. ${ }^{20}$ Predefined subgroup analyses were performed for the subgroup with comorbidity (osteoarthritis of the hip, low-back pain, or both).

All analyses were conducted using SAS version 9.2 (2007, Institute Inc, Cary, North Carolina, USA).

We aimed to include 150 participants (68 patients per group, and anticipating a $10 \%$ loss to follow-up) to be able to prove a difference of $25 \%$ for recovery (a recovery of $45 \%$ in the control group and $70 \%$ in the intervention group) based on 2 -sided testing with $\alpha$ of .05 and a power of $80 \%$. 


\section{RESULTS}

Figure 1 presents the participant flow of the study. From April 2006 until June 2008 general practitioners recruited 159 patients, 7 of whom did not meet our inclusion criteria. After reading the study information, 23 patients refused to participate, for the most part because they had a clear preference for either injection therapy or for usual care. Although the time between

\section{Figure 1. Participant flowchart.}

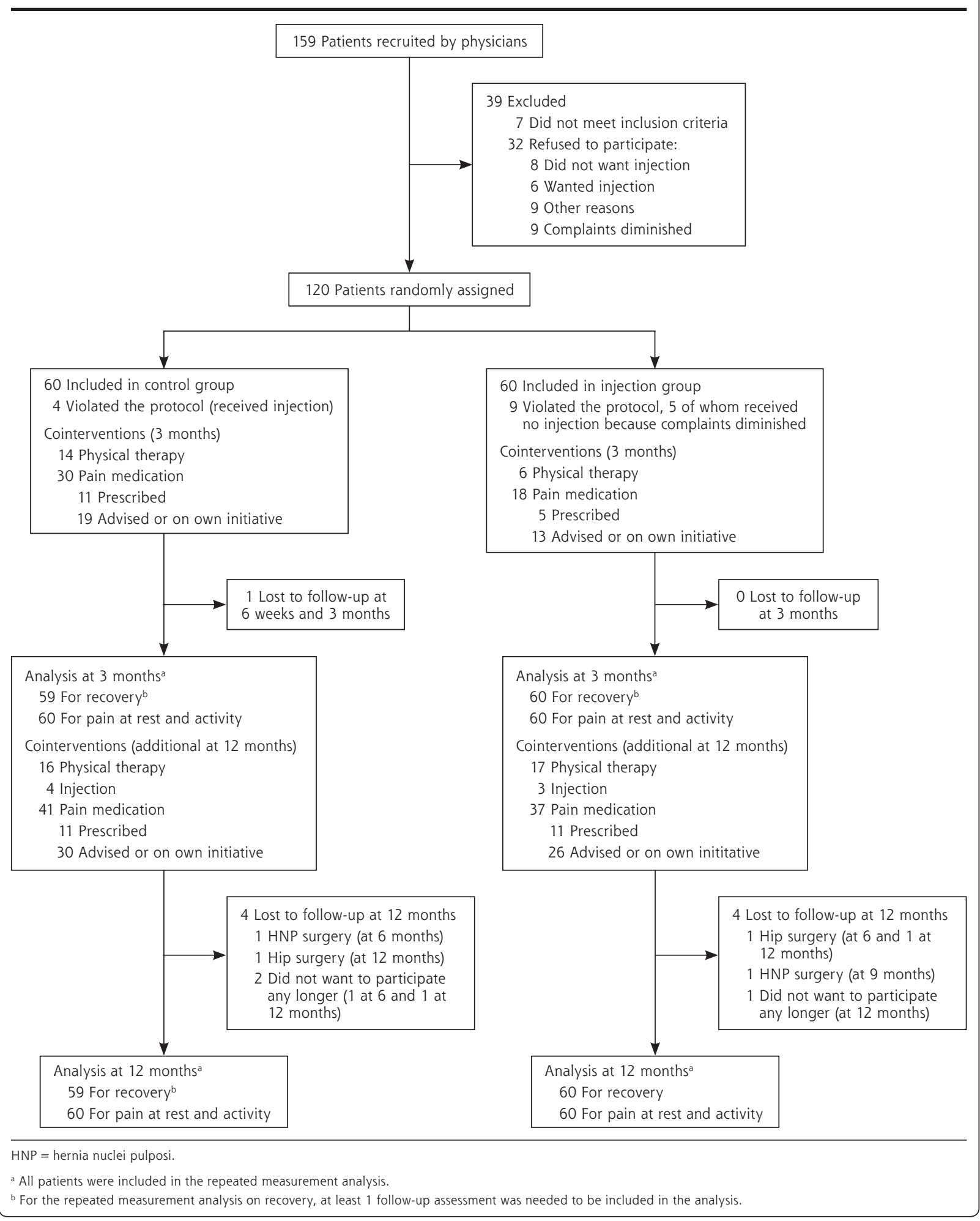


visiting their physician and randomization was only a few days, 5 patients had a spontaneous decline of their symptoms and therefore no longer wished to participate in the study.

Finally, 120 patients were included in the study and randomized (60 to usual care, 60 to injection therapy); their mean age was 56 years, and $77 \%$ of them were women (Table 1 displays their baseline characteristics). Complete follow-up data of the primary outcomes at 3 months were available for 119 patients and at 12 months for 111 patients.

During the first 3 months, 13 patients did not receive the intervention as allocated, and 9 patients did not receive the injection therapy. Of the latter group, 5 reported that their symptoms disappeared before the injection was given. In the usual care group 4 patients received an injection from their physician, which was contrary to study instructions.

Figure 2 shows the course of pain at rest and on activity up to 12 months of follow-up, and Figure 3 shows the course of recovery.

\section{Results at 3-Month Follow-up}

By the 3-month follow-up visit, 55\% of injection group patients had recovered (defined as totally or strongly recovered) compared with $34 \%$ of the usual care group (21\% difference), for a number needed to treat of 5 . None of the baseline variables, when added to the model, changed the outcome by more than $10 \%$. Binary models for recovery resulted in an odds ratio (OR) of 2.38 (95\% CI, 1.14-5.00) (Table 2). Pain severity at rest and on activity decreased in both groups; however, the decrease was greater in the injection group: adjusted difference for pain at rest was $\mathrm{OR}=1.18$ (95\% CI, 0.31$2.05)$ and adjusted difference for pain with activity was $\mathrm{OR}=1.30$ (95\% CI 0.32-2.29). Effect sizes for pain severity were 0.54 and 0.57 , respectively.

The estimates for the above-mentioned primary outcomes were slightly higher when violators of the protocol were excluded from the analysis. Similar results were found when those who did not receive the injection because their complaints had diminished $(n=5)$ were also excluded.
The secondary outcomes of WOMAC pain and WOMAC function measures showed a greater decrease in pain in the injection group than in the usual care group. The adjusted difference between the groups for WOMAC pain and WOMAC function were $\mathrm{OR}=12.40(95 \% \mathrm{CI}, 4.86-19.93)$ and $\mathrm{OR}=11.36$ (95\% CI, 4.01-18.70), respectively. Effect sizes for injection therapy were 0.67 and 0.56 , respectively. There was no significant difference in quality of life between the 2 groups (Table 2).

\section{Results at 12-Month Follow-up}

At the 12 -month follow-up visit, $61 \%$ of the patients in the injection group had recovered (defined as totally or strongly recovered) compared with $60 \%$ in the usual care group. Binary models for recovery resulted in $\mathrm{OR}=1.05$ (95\% $\mathrm{CI}, 0.50-2.27)$. Pain severity at rest and pain severity with activity decreased in both groups. The adjusted difference for pain at rest was $\mathrm{OR}=0.14(95 \% \mathrm{CI},-0.75$ to 1.04$)$, and the adjusted difference for pain with activity was $\mathrm{OR}=0.45$ (95\% CI, -0.55 to 1.46$)$. The differences were not significant, however. 
All secondary outcomes showed no differences at 12 months of follow-up (Table 2).

\section{Subgroup Analysis}

In the subgroup with comorbidity (hip osteoarthritis, low-back pain, or both; $\mathrm{n}=73$ ), $58 \%$ of the intervention group had recovered vs $32 \%$ in the usual care group at the 3 -month follow-up, with a number needed to treat of 4 (adjusted OR $=2.87 ; 95 \% \mathrm{CI}, 1.10-7.55)$. Differences in pain at rest and with activity at 3 months of follow-up were 1.36 (95\% CI, 0.15-2.57) and 1.42 (95\%
CI, 0.14-2.70), respectively. Effect sizes were 0.69 (pain at rest) and 0.67 (pain with activity).

Comparing the intervention group with the usual care group at the 12-month follow-up, differences in pain at rest and with activity were $0.12(95 \% \mathrm{CI},-1.12$ to 1.36$)$ and 1.42 (95\% CI, 0.14 to 2.70$)$, respectively. For recovery $\mathrm{OR}=0.99(95 \% \mathrm{CI}, 0.38-2.59)$.

\section{Adverse Effects}

At 6 weeks, the frequency of systemic adverse events was similar. In the injection group, no immediate

Figure 2. Course of mean pain intensity (and standard error) at rest and on activity during the 12-month follow-up period for injection group $(n=60)$ and usual care group $(n=59)$, on a visual analog scale (VAS)
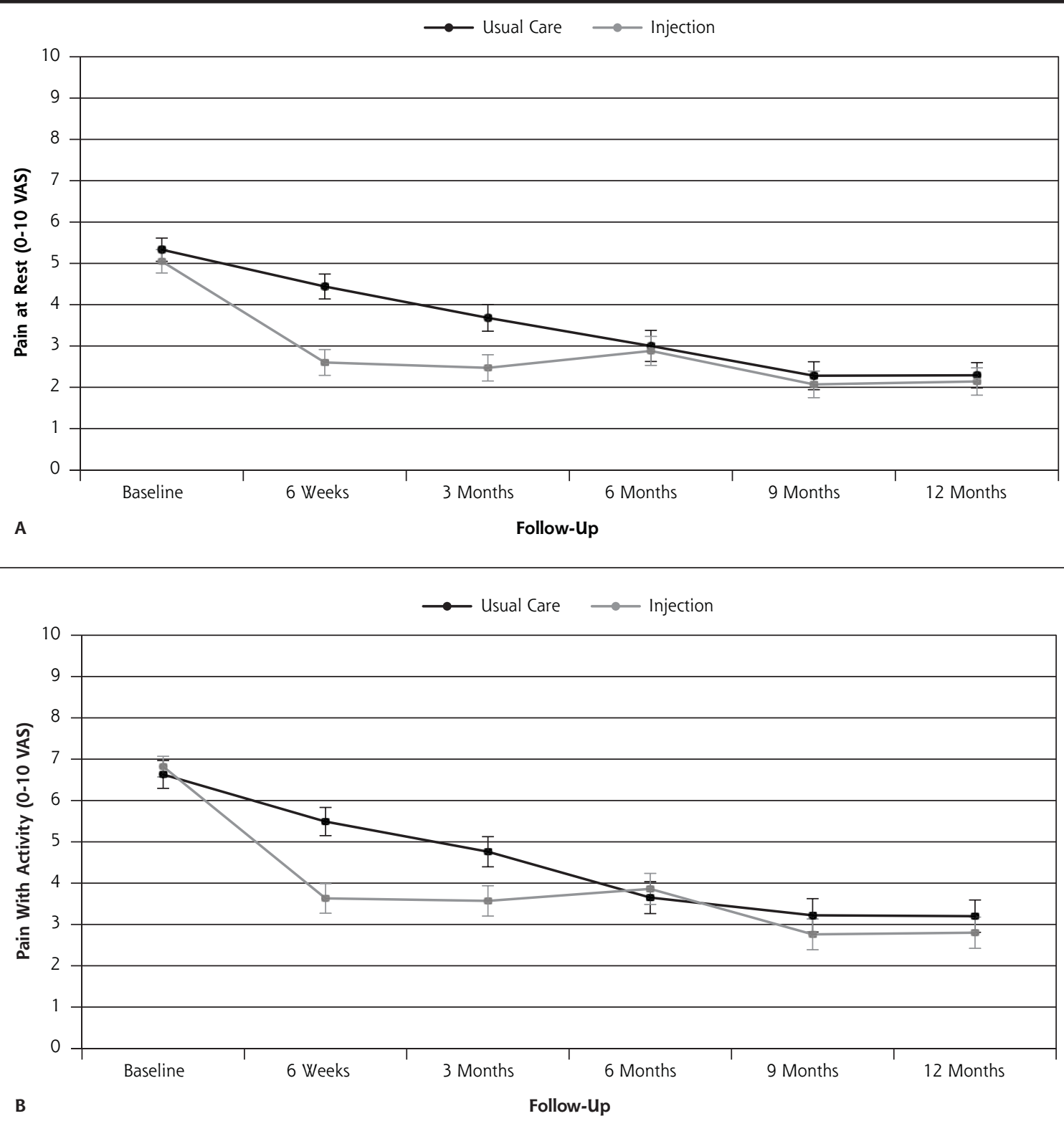
Figure 3. Course of recovery during 12-months for injection group $(n=60)$ and usual care group $(n=60)$.

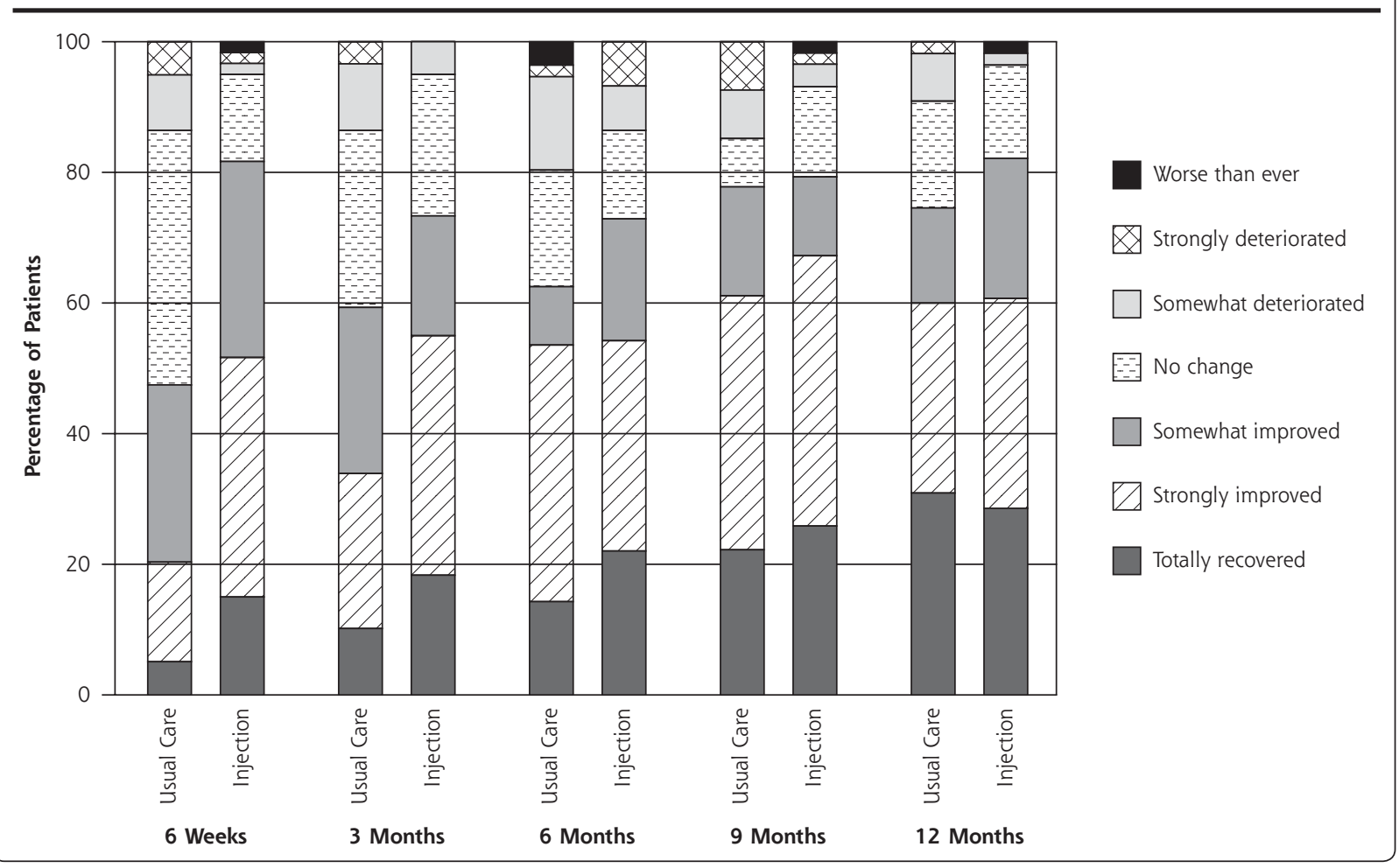

Table 2. Primary and Secondary Outcome Measures at the 3- and 12-Month Follow-up

\begin{tabular}{|c|c|c|c|c|c|c|c|c|}
\hline \multirow[b]{2}{*}{ Outcome } & \multicolumn{3}{|c|}{ Usual Care $(n=59)$} & \multicolumn{3}{|c|}{ Injection $(n=60)$} & \multirow{2}{*}{$\begin{array}{c}3 \mathrm{mo} \\
\text { OR }(95 \% \mathrm{Cl})\end{array}$} & \multirow{2}{*}{$\begin{array}{c}12 \mathrm{mo} \\
\text { OR }(95 \% \mathrm{Cl})\end{array}$} \\
\hline & Baseline & $3 \mathrm{mo}$ & $12 \mathrm{mo}$ & Baseline & $3 \mathrm{mo}$ & $12 \mathrm{mo}$ & & \\
\hline \multirow[t]{2}{*}{ Recovered,n/N (\%) } & - & $20 / 59(34)$ & $33 / 55(60)$ & - & $33 / 60(55)$ & $34 / 56(61)$ & $\begin{array}{c}2.38 \\
(1.14 \text { to } 5.00)\end{array}$ & $\begin{array}{c}1.05 \\
(0.50 \text { to } 2.27)\end{array}$ \\
\hline & & & & & & & $\begin{array}{l}\text { Difference } \\
\text { at } 3 \mathrm{mo} \\
(95 \% \mathrm{Cl})^{\mathrm{b}}\end{array}$ & $\begin{array}{l}\text { Difference } \\
\text { at } 12 \mathrm{mo} \\
(95 \% \mathrm{Cl})\end{array}$ \\
\hline $\begin{array}{l}\text { Pain at rest, } \\
\text { mean (SD) }\end{array}$ & $\begin{array}{l}5.3 \\
(2.2)\end{array}$ & $\begin{array}{c}3.7 \\
(2.5)\end{array}$ & $\begin{array}{l}2.3 \\
(2.3)\end{array}$ & $\begin{array}{l}5.1 \\
(2.2)\end{array}$ & $\begin{array}{c}2.5 \\
(2.5)\end{array}$ & $\begin{array}{l}2.1 \\
(2.5)\end{array}$ & $\begin{array}{c}1.18 \\
(0.31 \text { to } 2.05)\end{array}$ & $\begin{array}{c}0.14 \\
(-0.75 \text { to } 1.04)\end{array}$ \\
\hline $\begin{array}{l}\text { Pain with activity, } \\
\text { mean (SD)c }\end{array}$ & $\begin{array}{l}6.6 \\
(2.60)\end{array}$ & $\begin{array}{c}4.8 \\
(2.8)\end{array}$ & $\begin{array}{c}3.2 \\
(2.9)\end{array}$ & $\begin{array}{l}6.7 \\
(1.9)\end{array}$ & $\begin{array}{c}3.6 \\
(2.8)\end{array}$ & $\begin{array}{l}2.8 \\
(2.8)\end{array}$ & $\begin{array}{c}1.30 \\
(0.32 \text { to } 2.29)\end{array}$ & $\begin{array}{c}0.45 \\
(-0.55 \text { to } 1.46)\end{array}$ \\
\hline \multicolumn{9}{|l|}{ Secondary outcomes } \\
\hline $\begin{array}{l}\text { WOMAC pain, } \\
\text { mean (SD) }\end{array}$ & $\begin{array}{l}52.4 \\
(19.1)\end{array}$ & $\begin{array}{c}37.6 \\
(22.7)^{1}\end{array}$ & $\begin{array}{l}22.9 \\
(22.8)\end{array}$ & $\begin{array}{l}48.8 \\
(16.1)\end{array}$ & $\begin{array}{l}23.6 \\
(21.3)\end{array}$ & $\begin{array}{l}18 \\
(19.6)\end{array}$ & $\begin{array}{c}12.40 \\
(4.86 \text { to } 19.93)\end{array}$ & $\begin{array}{c}2.67 \\
(-4.98 \text { to } 10.32)\end{array}$ \\
\hline $\begin{array}{l}\text { WOMAC function, } \\
\text { mean (SD) }\end{array}$ & $\begin{array}{c}49.2 \\
(19.6)\end{array}$ & $\begin{array}{c}34.2 \\
(21.3)\end{array}$ & $\begin{array}{l}21.7 \\
(22.7)\end{array}$ & $\begin{array}{l}43.9 \\
(17.0)\end{array}$ & $\begin{array}{l}21.3 \\
(19.3)\end{array}$ & $\begin{array}{c}17.4 \\
(19.6)\end{array}$ & $\begin{array}{c}11.36 \\
\text { (4.01 to } 18.70)\end{array}$ & $\begin{array}{c}1.01 \\
(-6.37 \text { to } 8.39)\end{array}$ \\
\hline EQ-5D, mean (SD) & $\begin{array}{c}0.72 \\
(0.2)\end{array}$ & $\begin{array}{c}0.79 \\
(0.17)\end{array}$ & $\begin{array}{c}0.85 \\
(0.17)\end{array}$ & $\begin{array}{c}0.74 \\
(0.2)\end{array}$ & $\begin{array}{c}0.81 \\
(0.2)\end{array}$ & $\begin{array}{c}0.82 \\
(0.2)\end{array}$ & $\begin{array}{c}-0.02 \\
(-0.08 \text { to } 0.04)\end{array}$ & $\begin{array}{c}-0.004 \\
(-0.05 \text { to } 0.06)\end{array}$ \\
\hline
\end{tabular}

EQ-5D = a quality-of-life instrument from EuroQol; WOMAC = Western Ontario and McMaster Universities Osteoarthritis Index.

a Fully or strongly recovered.

${ }^{\mathrm{b}}$ Adjusted for baseline values of the outcome.

c Scored on a range from 0-10, where $0=$ no pain and $10=$ worst conceivable pain

a Scored on a range from 0-100, with high values indicating more pain or lower physical functioning.

e Scored on a range from $0-1$, where $0=$ worst quality of life and $1=$ best quality of life.

side-effects were reported by the physicians; however, almost $40 \%$ of the injection group reported a short period with superficial pain at the site of the injection (Table 3).

\section{DISCUSSION}

In this first randomized controlled trial assessing the effectiveness of corticosteroid injections vs usual care for patients with GTPS, a clinically relevant effect was 


\begin{tabular}{|lcc|}
\hline \multicolumn{2}{c}{ Table 3. Reported Number of Adverse Events at $\mathbf{6}$ Weeks } \\
\hline Adverse Event & $\begin{array}{c}\text { Intervention } \\
\text { Group }\end{array}$ & $\begin{array}{c}\text { Usual Care } \\
\text { Group }\end{array}$ \\
\hline Hot flushes & 11 & 12 \\
Disturbance in menstruation pattern & 3 & 5 \\
General allergic reaction (eg, itching & 9 & 12 \\
$\quad$ all over the body, urticaria, head- & & \\
ache, shortness of breath) & & 0 \\
Superficial pain at site of injection & 23 & 0 \\
$<1$ day & 3 & 0 \\
$\geq 1$ day & 11 & 0 \\
$\quad$ Missing & 1 & 0 \\
Other reported side-effects & 1 & 0 \\
Insensible spot & 1 & 0 \\
$\quad$ Extravasation of blood & 1 & \\
Sore spot & & \\
Small lump at injection place & & \\
\hline
\end{tabular}

by patients in clinical practice; therefore, it is not possible to distinguish among the effects of the injection itself (needling), or the use of lidocaine, the corticosteroid fluid, or the placebo effect. It is acknowledged that a placebo effect might occur with injection therapy. For example, a recent review reported that a more invasive placebo treatment was more effective than a noninvasive placebo treatment. ${ }^{22}$

In the present study, during the first 3 months more patients in the usual care group than in the intervention group received physical therapy (although not specifically recommended) as a cointervention; the same was true for pain medication. The effect of injection therapy may therefore be even stronger than reported here.

Observational studies have shown that

shown at 3 months of follow-up for recovery and for pain at rest and with activity. At 12 months of followup the differences in outcome were no longer present.

This randomized controlled trial is the first to compare the effect of local corticosteroid injections with usual care in primary care patients with GTPS. Even though we were unable to include the 150 patients that we hoped to randomize, ${ }^{21}$ we found a significant and clinically relevant effect of injection with corticosteroids at 3 months in all primary outcome measurements. Although this effect was even higher at 6 weeks, at the 12-month follow-up no difference in effect was present.

Our findings indicate a short-term effect of corticosteroid injections, which disappeared at 6 months. Rompe et al also found a short-term effect of corticosteroid injection at 1 month follow-up; however, this beneficial effect had decreased at 4 months, and by the 15-month follow-up visit the pain had increased again to almost baseline values. ${ }^{15}$ In contrast to our study, Rompe et al included patients from secondary care and excluded patients with concurrent hip joint disease. It remains uncertain whether his study population explains the difference between the 2 studies for the long-term course of complaints after corticosteroid injection.

Even though our inclusion period took longer than we anticipated, and we enrolled fewer than 150 participants, the funding authority allowed us to reduce the sample size to 120 participants because we had almost no loss to follow-up (especially on the short term). In view of the clear results, it is possible that a somewhat larger study population would not have led to different conclusions.

We used a pragmatic open design and measured the effect of the corticosteroid injection as experienced about two-thirds of patients with GTPS also have lowback pain or osteoarthritis of the hip. ${ }^{6,23}$ The present study also found comorbidity in $63 \%$ of the patients. Because we expected to find lower effectiveness in the subgroup, we prestratified our randomization for comorbidity. In our analysis of patients with comorbidity, however, the effect of injection therapy with corticosteroids was unexpectedly slightly higher and significant. This finding implies that the subgroup of patients with comorbidity profit as much from the injection therapy as did the total intervention group.

A systemic effect of corticosteroid injections on musculoskeletal pain has been proposed because (in patients with rotator cuff disease) a corticosteroid injection was found to be equally effective in the upper gluteal region and in the subacromial bursa. ${ }^{24}$ Apart from a beneficial effect on GTPS, in our patients with comorbidity, the injections might also have had a beneficial effect on osteoarthritis or low-back pain.

Because we aimed to interfere as little as possible with usual primary care practice, radiographs were not used to assess hip osteoarthritis. Instead, a clinical assessment was used to define osteoarthritis according to the ACR clinical criteria for hip osteoarthritis. ${ }^{25}$ Because these criteria were not developed for primary care research, our clinical classification may not fully overlap with the ACR radiographic classification criteria $^{17}$; nevertheless, they are the most suitable clinical criteria currently available. ${ }^{26}$ Our assessment of low-back pain was based on the questionnaire alone, and we have no information about the type and severity of that pain. We can conclude, however, that other musculoskeletal symptoms of the hip (eg, morning stiffness or painful or restricted internal rotation) or in the low-back region should not prevent the clinician from applying local injection therapy when GTPS is diagnosed. 
In our study no serious adverse effects of the injection therapy was observed. Our injection group is relatively small, and the follow-up time was short, so we cannot draw conclusions about the safety of our procedure. A recent review about adverse effects of extra-articular corticosteroid injection concluded that corticosteroid injection therapy is relatively safe if it is administered in a professional way. ${ }^{27}$

In the present study, 14 patients meeting the inclusion criteria decided not to participate because of their strong preference for a specific therapy. Preference for the type of intervention did not influence the effect of the corticosteroid injection by more than $10 \%$ but, again, many patients with a strong preference for a specific therapy chose not to participate in the study.

\section{Recommendations for General Practice}

This study shows the additional value of injection therapy in primary care patients who have clinical signs of GTPS. The application of corticosteroid injections made no difference in the long-term resolution of pain, but the injection gave patients early relief. Although these effects have been assessed in only one trial, physicians now have a more evidence-based rationale for offering corticosteroid injections to patients with symptoms of GTPS for the short-term relief of symptoms.

To read or post commentaries in response to this article, see it online at http://www.annfammed.org/cgi/content/full/9/3/226.

Key words: Greater trochanteric pain syndrome; bursitis trochanterica; glucocorticorticosteroids; injection, adverse event

Submitted June 6, 2010; submitted, revised October 13, 2010; accepted November 29, 2010.

Funding support: This study was supported by the funding program for common disorders in general practice by the Netherlands Organization for Health Research and Development (ZonMW).

Disclaimer: The funding source had no involvement in the collection, analysis, and interpretation of data, or in the decision to submit the paper for publication.

\section{References}

1. Anderson TP. Trochanteric bursitis: diagnostic criteria and clinical significance. Arch Phys Med Rehabil. 1958;39(10):617-622.

2. Little H. Trochanteric bursitis: a common cause of pelvic girdle pain. Can Med Assoc J. 1979;120(4):456-458

3. Schapira D, Nahir M, Scharf Y. Trochanteric bursitis: a common clinical problem. Arch Phys Med Rehabil. 1986;67(11):815-817.

4. Shbeeb MI, Matteson EL. Trochanteric bursitis (greater trochanter pain syndrome). Mayo Clin Proc. 1996;71(6):565-569.

5. Karpinski MR, Piggott $\mathrm{H}$. Greater trochanteric pain syndrome. A report of 15 cases. J Bone Joint Surg Br. 1985;67(5):762-763.

6. Collée G, Dijkmans BA, Vandenbroucke JP, Cats A. Greater trochanteric pain syndrome (trochanteric bursitis) in low back pain. Scand J Rheumatol. 1991;20(4):262-266.
7. Silva F, Adams T, Feinstein J, Arroyo RA. Trochanteric bursitis: refuting the myth of inflammation. J Clin Rheumatol. 2008;14(2):82-86.

8. Bierma-Zeinstra SM, Bohnen AM, Bernsen RM, Ridderikhoff J, Verhaar JA, Prins A. Hip problems in older adults: classification by cluster analysis. J Clin Epidemiol. 2001;54(11):1139-1145.

9. Bird PA, Oakley SP, Shnier R, Kirkham BW. Prospective evaluation of magnetic resonance imaging and physical examination findings in patients with greater trochanteric pain syndrome. Arthritis Rheum. 2001;44(9):2138-2145.

10. Cohen SP, Strassels SA, Foster L, et al. Comparison of fluoroscopically guided and blind corticosteroid injections for greater trochanteric pain syndrome: multicentre randomised controlled trial. BMJ. 2009;338:b1088

11. Segal NA, Felson DT, Torner JC, et al.; Multicenter Osteoarthritis Study Group. Greater trochanteric pain syndrome: epidemiology and associated factors. Arch Phys Med Rehabil. 2007;88(8):988-992.

12. Lievense A, Bierma-Zeinstra S, Schouten B, Bohnen A, Verhaar J, Koes B. Prognosis of trochanteric pain in primary care. $\mathrm{Br} / \mathrm{Gen}$ Pract. 2005;55(512):199-204.

13. Shbeeb MI, O’Duffy JD, Michet CJ Jr, O’Fallon WM, Matteson EL. Evaluation of glucocorticosteroid injection for the treatment of trochanteric bursitis. J Rheumatol. 1996;23(12):2104-2106.

14. Gordon EJ. Trochanteric bursitis and tendinitis. Clin Orthop. 1961; 20:193-202.

15. Rompe JD, Segal NA, Cacchio A, Furia JP, Morral A, Maffulli N. Home training, local corticosteroid injection, or radial shock wave therapy for greater trochanter pain syndrome. Am J Sports Med. 2009;37(10):1981-1990.

16. Brinks A, van Rijn RM, Bohnen AM, et al. Effect of corticosteroid injection for trochanter pain syndrome: design of a randomised clinical trial in general practice. BMC Musculoskelet Disord. 2007;8:95.

17. Bierma-Zeinstra S, Bohnen A, Ginai A, Prins A, Verhaar J. Validity of American College of Rheumatology criteria for diagnosing hip osteoarthritis in primary care research. J Rheumatol. 1999;26(5):1129-1133.

18. EuroQol-a new facility for the measurement of health-related quality of life. The EuroQol Group. Health Policy. 1990;16(3):199-208

19. Roorda LD, Jones CA, Waltz M, et al. Satisfactory cross cultural equivalence of the Dutch WOMAC in patients with hip osteoarthritis waiting for arthroplasty. Ann Rheum Dis. 2004;63(1):36-42.

20. Felson DT, Anderson JJ, Boers M, et al. American College of Rheu matology. Preliminary definition of improvement in rheumatoid arthritis. Arthritis Rheum. 1995;38(6):727-735.

21. Tognoni G, Alli C, Avanzini F, et al. Randomised clinical trials in general practice: lessons from a failure. BMJ. 1991;303(6808):969-971.

22. Zhang W, Robertson J, Jones AC, Dieppe PA, Doherty M. The placebo effect and its determinants in osteoarthritis: meta-analysis of randomised controlled trials. Ann Rheum Dis. 2008;67(12):1716-1723.

23. Ege Rasmussen KJ, Fanø N. Trochanteric bursitis. Treatment by corticosteroid injection. Scand J Rheumatol. 1985;14(4):417-420.

24. Ekeberg OM, Bautz-Holter E, Tveitå EK, Juel NG, Kvalheim S Brox Jl. Subacromial ultrasound guided or systemic steroid injection for rotator cuff disease: randomised double blind study. BMJ. 2009;338:a3112.

25. Altman R, Alarcón G, Appelrouth D, et al. The American College of Rheumatology criteria for the classification and reporting of osteoarthritis of the hip. Arthritis Rheum. 1991;34(5):505-514.

26. Reijman M, Hazes JM, Koes BW, Verhagen AP, Bierma-Zeinstra SM. Validity, reliability, and applicability of seven definitions of hip osteoarthritis used in epidemiological studies: a systematic appraisal. Ann Rheum Dis. 2004;63(3):226-232.

27. Brinks A, Koes BW, Volkers AC, Verhaar JA, Bierma-Zeinstra SM. Adverse effects of extra-articular corticosteroid injections: a systematic review. BMC Musculoskelet Disord. 2010;11(1):206. 